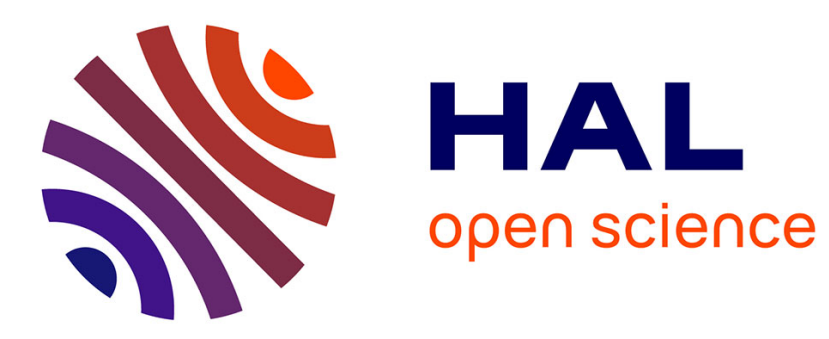

\title{
Compact Planar Arrays Based on Parasitic Superdirective Elements
}

Abdullah Haskou, Ala Sharaiha, Sylvain Collardey

\section{To cite this version:}

Abdullah Haskou, Ala Sharaiha, Sylvain Collardey. Compact Planar Arrays Based on Parasitic Superdirective Elements. European Conference on Antennas and Propagation, Apr 2016, Davos, Switzerland. hal-01314974

\section{HAL Id: hal-01314974 \\ https://hal.science/hal-01314974}

Submitted on 12 May 2016

HAL is a multi-disciplinary open access archive for the deposit and dissemination of scientific research documents, whether they are published or not. The documents may come from teaching and research institutions in France or abroad, or from public or private research centers.
L'archive ouverte pluridisciplinaire HAL, est destinée au dépôt et à la diffusion de documents scientifiques de niveau recherche, publiés ou non, émanant des établissements d'enseignement et de recherche français ou étrangers, des laboratoires publics ou privés. 


\title{
Compact Planar Arrays Based on Parasitic Superdirective Elements
}

\author{
Abdullah Haskou, Ala Sharaiha, and Sylvain Collardey \\ IETR UMR CNRS 6164- Université de Rennes 1, Rennes, France \\ abdullah.haskou@univ-rennes1.fr, ala.sharaiha@univ-rennes1.fr, sylvain.collardey@univ-rennes1.fr
}

\begin{abstract}
This paper addresses the problem of designing compact antenna arrays for UHF band by using small superdirective unit-elements. A small parasitic two-element array is designed for $868 \mathrm{MHz}$ European RFID band. This array with a size factor $(k a=1.1)$ has a total directivity of $7 d B i$ and radiation efficiency of $43.4 \%$. Then this array is integrated in a $2 \times 2$ planar array. A parametric analysis on the interelement distance is performed revealing the tradeoffs between the antenna- dimensions, -directivity and -efficiency. A small $2 \times 2$ antenna array with dimensions of $34 \times 34 \mathrm{~cm}^{2}$ presenting a total directivity of $12.6 \mathrm{~dB} i$ and radiation efficiency of $41 \%$ is designed.
\end{abstract}

Keywords-Superdirectivity, parasitic-element, directivity, radiation efficiency

\section{INTRODUCTION}

Reducing the size of antenna arrays is always of a great interest in the antenna engineering community. However, the conventional techniques for enhancing the directivity of arrays lead to a significant increase in their size. At the same time, there has been renewed interest in superdirective arrays and in particular electrically small superdirective arrays [1]-[11]. In [11] we detailed the design procedure of small parasitic superdirective arrays. In this paper, we propose a new strategy for designing compact arrays by using small superdirective arrays as unit-elements. The constraints including the maximum directivity, the efficiency, the predefined number of elements and the distance between the elements are studied. Results are validated through the realization and measurement of a $2 \times 2$ array. ${ }^{1}$

\section{UNIT-ELEMENT DESCRIPTION}

The initial antenna used in the designed array is a miniaturized half-loop antenna printed on a $0.8 \mathrm{~mm}$-thick Rogers RO4003 substrate [7] and integrated in a PCB of $8 \times 8 \mathrm{~cm}^{2}$ as shown in Fig. 1(a). It has a simulated (ANSYS HFSS [12]) resonance around $864 \mathrm{MHz}$ as shown in Fig. 1(c). Fig. 1(d) shows the antenna surface current distribution (the same color range will be used from now on). As it can be noticed, the current on the ground plane is mainly following Yo direction, hence, it acts as a monopole in the XoY plane and following the Y-axis. This explains the omnidirectional radiation in the $\mathrm{XoZ}$ direction and the null in the oY direction in the antenna far-field radiation pattern given in Fig. 1(e). The null is slightly rotated toward $\mathrm{X}$-axis due to the edges radiation. The antenna

\footnotetext{
${ }^{1}$ This work was done with the funding of the French National Research Agency as part of the project "SOCRATE" and the support of the "Images et Reseaux" cluster of Brittany region, France.
}

has a directivity of $2.4 \mathrm{dBi}$ and radiation efficiency of $89.4 \%$. A prototype of the antenna was fabricated and measured for results validation (Fig. 1(b)). Fig. 1(c) shows the measured input reflection coefficient magnitude in $\mathrm{dB}$. The measured resonance is at $881 \mathrm{MHz}$ (a shift of $2 \%$ compared to the simulation). The antenna far field radiation pattern was measured in SATIMO Stargate SG 32 near field measurement system. The measured 3D total directivity radiation pattern at the resonance is given in Fig. 1(e). The measured directivity is $3.1 \mathrm{dBi}$. For more insight the antenna $2 \mathrm{D}$ total directivity radiation patterns in $\mathrm{E}(\mathrm{XoZ})$ and $\mathrm{H}$ (YoZ) planes are given in Fig. 2. The antenna radiation efficiency measured in a reverberation chamber [13] is about $75 \%$.

\section{Parasitic Superdirective Unit-Element DESIGN}

Two elements of the above-mentioned antenna are stacked along Z-axis with an inter-element distance $d_{1}$ is varying from $0.69 \mathrm{~cm}$ to $6 \mathrm{~cm}$. Fig. 3(a) shows the effect of the inter-element distance on the resonance frequency. We note that for very small distances, the resonance is shifted to $910 \mathrm{MHz}$ and as the distance increases this resonance converges to the one of the unit-element. Fig. 3(b) shows the array directivity as a function of the distance. As it can be noticed, the driven array directivity is maximal for small distances and as the distance increases this directivity decreases. The parasitic (loaded) array directivity is close to the fully-driven one till $3.5 \mathrm{~cm}$ where a negative resistance is required and neglecting this resistance significantly decreases the array directivity. As for the array efficiency, it increases as the distance increases (Fig. 3(c)). This is due to the decrement in the mutual coupling and the disturbance in the superdirectivity phenomena. Based on this study and as compromise between the antenna- directivity and efficiency, we optimized a two-element array for $868 \mathrm{M} \mathrm{Hz}$ European RFID frequency band with an inter-element distance of $2.5 \mathrm{~cm}(0.07 \lambda)$ as shown in Fig. 4(a). In this array, the first element is excited while the second is loaded by $3.3 p F$. Fig. 4(c) shows the antenna simulated input reflection coefficient magnitude in $\mathrm{dB}$. As it can be noticed, the antenna has a resonance at $868 \mathrm{MHz}$. Fig. 4(d) shows the antenna surface current distribution. The figure shows that the current on the two elements is out of phase which is the condition for having superdirectivity for very small inter-element distance. Fig. 4(e) shows the antenna 3D total directivity radiation pattern. The figure demonstrates a directive pattern with a directivity of $7 \mathrm{dBi}$ toward $\mathrm{z}$-axis. This directivity is $1.9 \mathrm{~dB}$ greater than Harrington's normal directivity limit [14] for an antenna with the same size factor $(k a=1.1)$. The HPBW in $\mathrm{E}(\mathrm{XoZ})$ and $\mathrm{H}$ (YoZ) planes are respectively $100^{\circ}$ and $86^{\circ}$ and FBR is $8.2 d B$. 


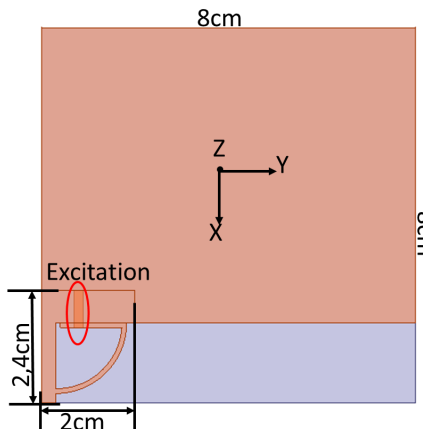

(a)

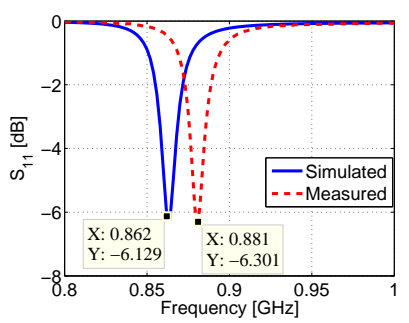

(c)

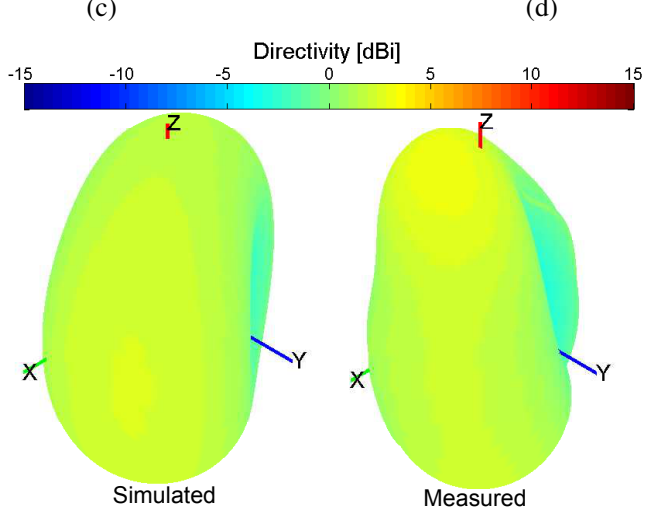

(e)

Fig. 1. The unit-element simulated and measured parameters. (a) Geometry and dimensions, (b) fabricated prototype, (c) input reflection coefficient magnitude in $\mathrm{dB}$, (d) surface current distribution and (e) 3D total directivity radiation pattern.

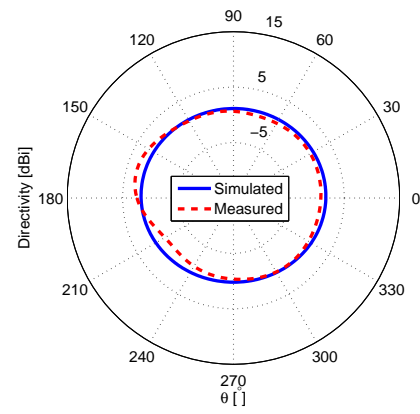

(a)

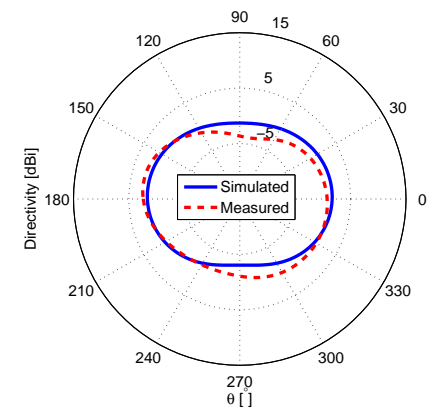

(b)
Fig. 2. The unit-element simulated and measured $2 \mathrm{D}$ total directivity radiation pattern. (a) E plane and (b) $\mathrm{H}$ plane.

Due to the current opposition, the antenna presents a radiation efficiency of $43.4 \%$.

A prototype of the antenna was fabricated and measured (Fig.

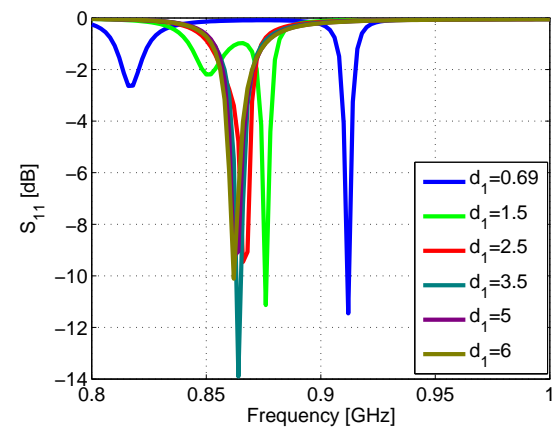

(a)

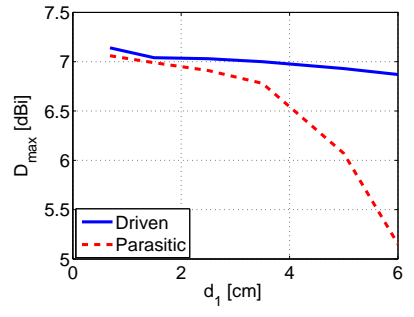

(b)

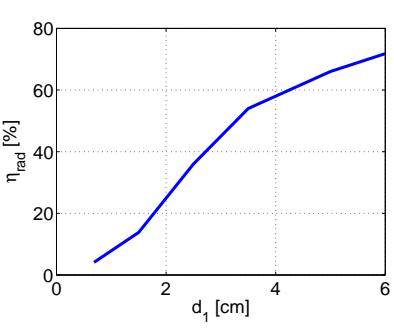

(c)
Fig. 3. Parasitic two-element array parameters as a function of the interelement distance. (a) simulated input reflection coefficient magnitude in $\mathrm{dB}$, (c) total directivity, and (c) radiation efficiency.

4(b)). Fig. 4(c) shows the antenna measured input reflection coefficient magnitude in $\mathrm{dB}$. The measured resonance is at $880 \mathrm{MHz}$ (a shift of $1.4 \%$ compared to the simulation). The antenna measured 3D total directivity radiation pattern at the resonance is given in Fig. 4(e). The measured directivity is $6.5 d B i$. The HPBW in $\mathrm{E}$ and $\mathrm{H}$ planes are respectively $95.6^{\circ}$ and $84^{\circ}$ and FBR is $6.7 d B$ (Fig. 5). The antenna radiation efficiency measured in a reverberation chamber is about $40 \%$.

\section{Planar ARray Design}

Four elements of the precedent parasitic array are integrated in $2 \times 2$ planar array as shown in Fig. 6(a). The spacing between the elements $d$ (calculated between the excitation ports) is changed from $12 \mathrm{~cm}$ to $30 \mathrm{~cm}$. Fig. 6(c) shows the mutual coupling as a function of the distance. As expected, the figure shows a higher coupling for small separations and as the distance increases the coupling decreases. Fig. 6(e) shows the antenna maximum directivity as a function of the distance. As the distance increases the coupling effect decreases and the achieved directivity increases till it reaches its maximum value around $0.8 \lambda$ where it starts decreasing again. As for the antenna efficiency, as the distance increases it decrease (Fig. 6(f)). This is mainly due to the lost of the superdirectivity for small distances (superdirectivity is achieved by a current opposition on the two unit-elements (Fig. 4(d)) which cancels the antenna radiation in some directions and hence reduces its efficiency). Finally, Fig. 7 shows the 3D total directivity radiation pattern for a distance of $26 \mathrm{~cm} \approx 0.75 \lambda$. The achieved directivity is $12.6 \mathrm{~dB} i$, and the radiation efficiency is $41 \%$. The $\mathrm{HPBW}$ in $\mathrm{E}(\mathrm{XoZ})$ and $\mathrm{H}(\mathrm{YoZ})$ planes are respectively $37^{\circ}$ and $35^{\circ}$ and FBR is $8.9 d B$ and the Side Lobe Level (SLL) is $3.2 d B$. 


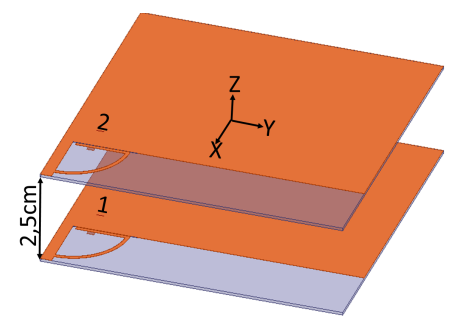

(a)

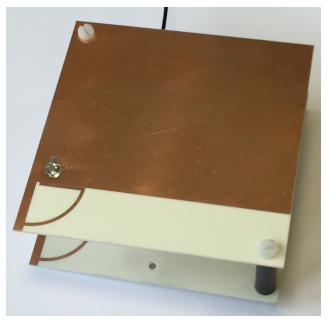

(b)

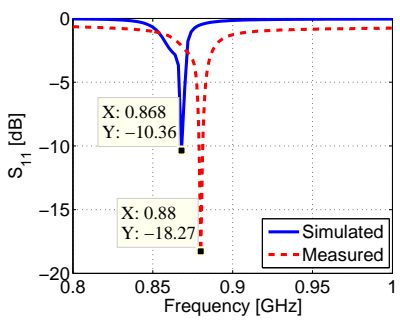

(c)

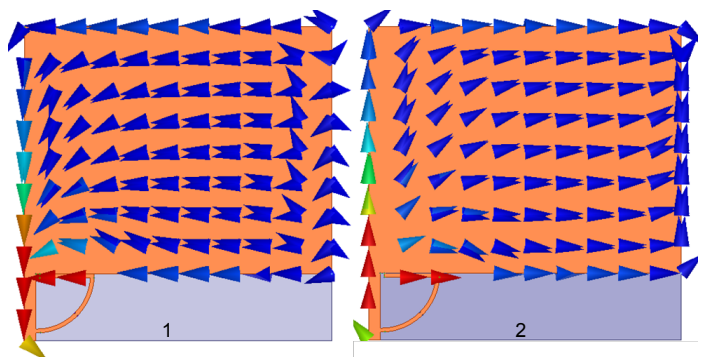

(d)

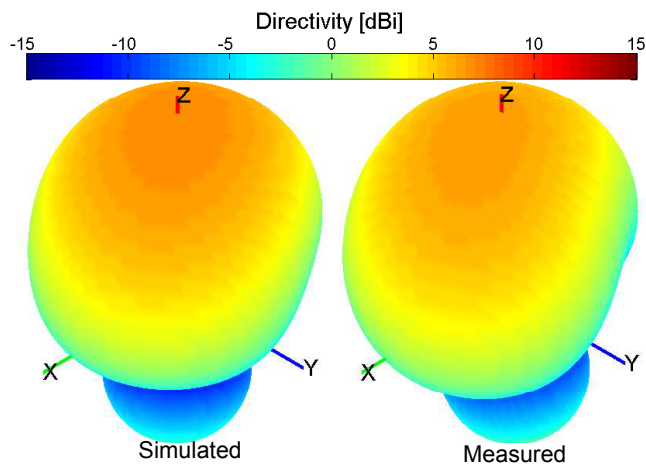

(e)

Fig. 4. Two-element array with $2.5 \mathrm{~cm}$ spacing simulated and measured parameters. (a) Geometry and dimensions, (b) fabricated prototype, (c) input reflection coefficient magnitude in $\mathrm{dB}$, (d) surface current distribution and (e) $3 \mathrm{D}$ total directivity radiation pattern.

A prototype of the antenna was fabricated and measured (Fig. 6(b)). A power divider from Mini-Circuits [15] and UFL cables are used for the feeding system. Fig. 6(d) shows the antenna with the feeding system measured input reflection coefficient magnitude in $\mathrm{dB}$. As it can be noticed, the resonance frequency is always at $879 \mathrm{MHz}$. It can also be noticed that the feeding system introduces a loss of about $1.5 d B$. This loss is due to the UFL cable, the power divider and the coaxial connections. The antenna directivity given in Fig. 6(e) shows the same trend as in the simulation. The antenna measured 3D total directivity for a distance of $26 \mathrm{~cm}$ is in a good agreement with the simulated one (Fig. 7). The measured directivity is $12.1 \mathrm{dBi}$. The HPBW

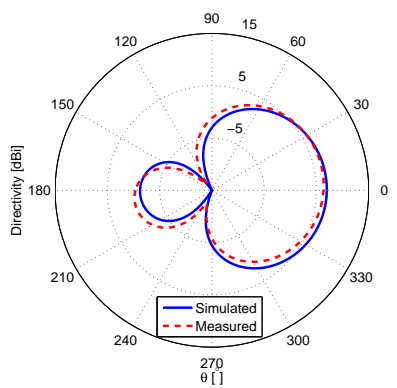

(a)

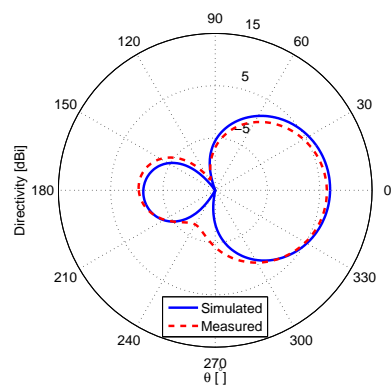

(b)
Fig. 5. Two-element array with $2.5 \mathrm{~cm}$ spacing simulated and measured $2 \mathrm{D}$ total directivity radiation pattern. (a) E plane and (b) $\mathrm{H}$ plane.

in $\mathrm{E}$ and $\mathrm{H}$ planes are respectively $39.4^{\circ}$ and $33.8^{\circ}$ and FBR is $18.8 \mathrm{~dB}$ (Fig. 8). The antenna reveals a measured radiation efficiency (also in a reverberation chamber) of about $39.8 \%$ after compensating the losses in the feeding system.

In all cases, the small difference between the simulated and measured results is due to the measurement environment (the connector, the excitation cable, ..), the measurement incertitude and the tolerance on the reference antennas' parameters namely directivity for radiation pattern measurement and radiation efficiency in the efficiency measurement.

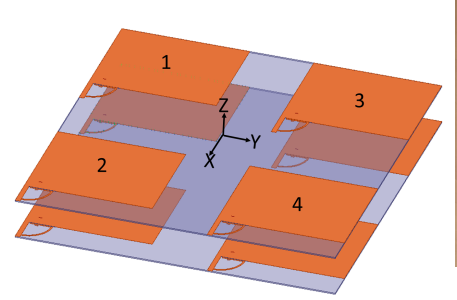

(a)

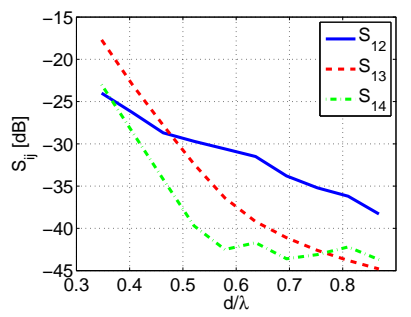

(c)

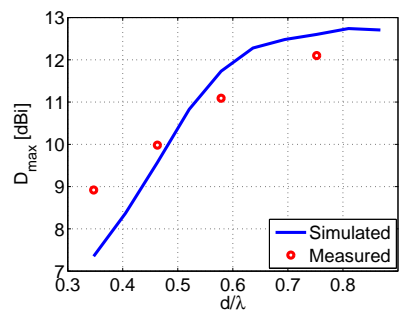

(e)

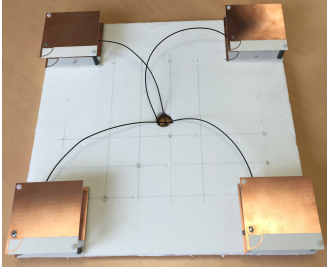

(b)

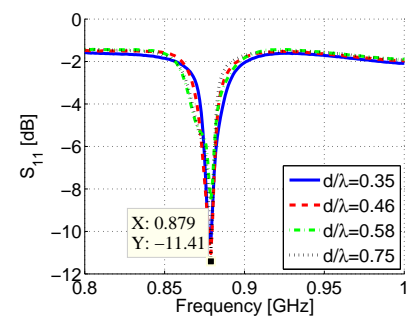

(d)

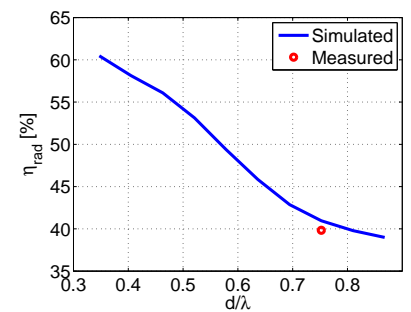

(f)

Fig. 6. Planar array simulated and measured parameters as a function of the separation. (a) Geometry, (b) fabricated prototype, (c) mutual coupling, (d) input reflection coefficient magnitude in $\mathrm{dB}$, (e) total directivity and (f) radiation efficiency. 


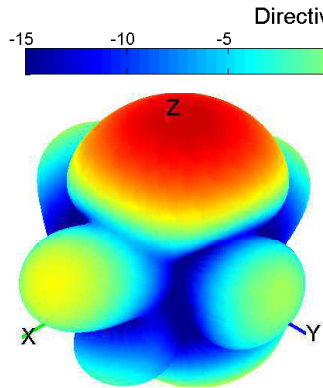

(a)

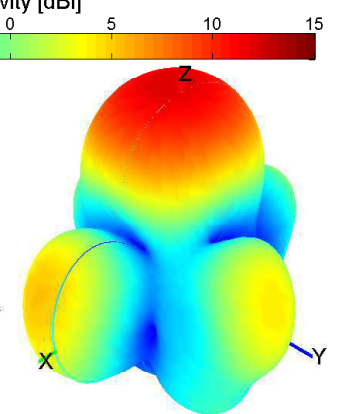

(b)
Fig. 7. Planar array $3 \mathrm{D}$ total directivity radiation pattern for $\mathrm{d}=26 \mathrm{~cm}$. (a) Simulated and (b) measured.

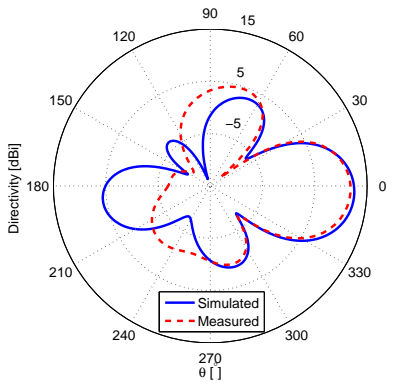

(a)

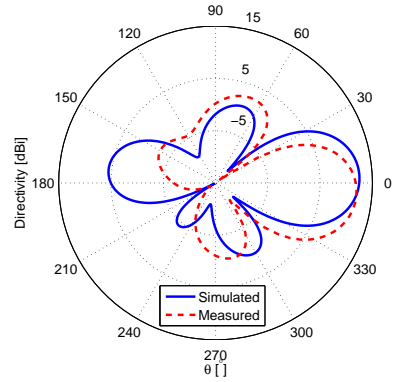

(b)
Fig. 8. Planar array $2 \mathrm{D}$ total directivity radiation pattern for $\mathrm{d}=26 \mathrm{~cm}$. (a) $\mathrm{E}$ plane and (b) $\mathrm{H}$ plane.

\section{CONCLUSION}

In this paper, a two-element parasitic superdirective antenna array was designed. These array was later integrated in $2 \times 2$ planar antenna array. A parametric analysis on the interelement distance revealed the tradeoffs between the antenna dimensions, directivity and efficiency. For an inter-element distance of $26 \mathrm{~cm}$ and for total dimensions of $34 \times 34 \mathrm{~cm}^{2}$ a total directivity of $12.6 \mathrm{dBi}$ and radiation efficiency of $41 \%$ were achieved. This antenna is significantly smaller than classic arrays with the same directivity.

\section{ACKNOWLEDGMENT}

The authors would like to thank Mr. Jérôme Sol from IETR UMR CNRS 6164- INSA de Rennes for all the time he dedicated to the measurements presented in this manuscript.

\section{REFERENCES}

[1] E. E. Altshuler, T. H. O’Donnell, A.D. Yaghjian, and S. R. Best, "A Monopole Superdirective Array", IEEE Transactions on Antennas and Propagation, vol. 53, no. 8, pp. 2653-2661, August 2005.

[2] T. H. O'Donnell, and A. D. Yaghjian, "Electrically Small Superdirective Arrays Using Parasitic Elements", IEEE Antennas and Propagation Society International Symposium 2006, pp. 3111,3114, 9-14 July 2006.

[3] S. Lim, and H. Ling, "Design of Electrically Small Yagi Antenna", Electronics Letters, vol. 43, no. 5, pp. 3-4, 1 March 2007.

[4] A. D. Yaghjian, T. H. O’Donnell, E. E. Altshuler, and S. R. Best "Electrically Small Supergain End-Fire Arrays", Radio Science, vol. 43, 2008.

[5] P. Sharma, D. Arora, and H. Gupta, "Designing Superdirective Patch Antenna Array Using Metamaterial", International Journal of Engineering Research \& Technology (IJERT), vol. 1, issue 8, October 2012.
[6] O. S. Kim, S. Pivnenko, and O. Breinbjerg, "Superdirective Magnetic Dipole Array as a First-Order Probe for Spherical Near-Field Antenna Measurements", IEEE Transactions on Antennas and Propagation, vol. 60, no. 10, pp. 4670-4676, October 2012.

[7] B. Sentucq, A. Sharaiha, and S. Collardey, "Superdirective Compact Parasitic Array of Metamaterial-Inspired Electrically Small Antenna", International Workshop on Antenna Technology (iWAT), pp. 269,272, 4-6 March 2013.

[8] M. Pigeon, A. Sharaiha, and S. Collardey, "Miniature and Superdirective Two Elements Endfire Antenna Array", 8th European Conference on Antennas and Propagation (EuCAP 2014), pp. 3553-3556, 6-11 April 2014.

[9] A. Haskou, A. Clemente, A. Sharaiha, C. Delaveaud, S. Collardey, and L. Rudant, "A Parasitic Three-Element Superdirective Electrically Small Antenna Array, Proceedings of Ninth European Conference on Antennas and Propagation (EuCAP 2015), pp. 1-4, 12-17 April 2015.

[10] A. Clemente, M. Pigeon, L. Rudant, and C. Delaveaud, "Design of a Super Directive Four-Element Compact Antenna Array Using Spherical Wave Expansion, IEEE Transactions on Antennas and Propagation, vol. 63, no. 11, pp. 4715-4722, November 2015.

[11] A. Haskou, A. Sharaiha, and S. Collardey, "Design of Small Parasitic Loaded Superdirective End-Fire Antenna Arrays", IEEE Transactions on Antennas and Propagation, vol. 63, no. 12, pp. 5456-5464, December 2015.

[12] ANSYS HFSS, Pittsburg, PA 15219, USA.

[13] G. Le Fur, C. Lemoine, P. Besnier, A. Sharaiha, "Performances of UWB Wheeler Cap and Reverberation Chamber to Carry Out Efficiency Measurements of Narrowband Antennas", IEEE Antennas and Wireless Propagation Letters, vol. 8, pp. 332,335, 2009.

[14] R. F. Harrington, "On the Gain and Beamwidth of Directional Antennas", IRE Transactions on Antennas and Propagation, pp. 219-225, July 1958.

[15] http://194.75.38.69/pdfs/ZN4PD-920W.pdf 